University of South Florida

DIGITAL COMMONS

Digital Commons @ University of

@ UNIVERSITY OF SOUTH FLORIDA

South Florida

Academic Services Faculty and Staff

Publications

Tampa Library

January 2007

\title{
Ontogenetic change in novel functions: waterfall climbing in adult Hawaiian gobiid fishes
}

\author{
R Blob \\ Saint Cloud State University \\ K M. Wright \\ University of South Florida, msheff@clemson.edu \\ M Becker \\ Saint Cloud State University \\ T Maie \\ Clemson University
}

T J. Iverson

Saint Cloud State University

See next page for additional authors

Follow this and additional works at: https://digitalcommons.usf.edu/tlas_pub

Part of the Biomechanics Commons, and the Evolution Commons

\section{Scholar Commons Citation}

Blob, R; Wright, K M.; Becker, M; Maie, T; Iverson, T J.; Julius, M L.; and Schoenfuss, H L., "Ontogenetic change in novel functions: waterfall climbing in adult Hawaiian gobiid fishes" (2007). Academic Services Faculty and Staff Publications. 43.

https://digitalcommons.usf.edu/tlas_pub/43

This Article is brought to you for free and open access by the Tampa Library at Digital Commons @ University of South Florida. It has been accepted for inclusion in Academic Services Faculty and Staff Publications by an authorized administrator of Digital Commons @ University of South Florida. For more information, please contact digitalcommons@usf.edu. 


\section{Authors}

R Blob, K M. Wright, M Becker, T Maie, T J. Iverson, M L. Julius, and H L. Schoenfuss 


\section{Ontogenetic Change in a Novel Function:}

\section{Waterfall Climbing in Adult Hawaiian Gobiid Fishes}

Richard W. Blob ${ }^{1}$, K. Megan Wright ${ }^{1}$, Marc Becker ${ }^{2}$, Takashi Maie ${ }^{1}$, Theresa J. Iverson ${ }^{2}$, Matthew L. Julius ${ }^{2}$, and Heiko L. Schoenfuss ${ }^{2}$

${ }^{1}$ Department of Biological Sciences, Clemson University, Clemson, SC, 29634, USA

${ }^{2}$ Department of Biological Sciences, St. Cloud State University, Math and Science Center, St. Cloud, MN, 56301, USA

LRH: Blob et al.

$\mathrm{RRH}$ : Ontogeny of waterfall climbing in gobiid fishes

Keywords

locomotion, performance, kinematics, ontogeny, climbing, biomechanics, fish, muscle

Address correspondence to:

Richard W. Blob

Department of Biological Sciences, Clemson University, 132 Long Hall, Clemson, SC, 29634, USA

Tel: $+1(864) 656-3602$

Fax: $+1(864) 656-0435$

E-mail: rblob@clemson.edu 


\section{Abstract}

Juveniles from three species of Hawaiian gobiid fishes climb waterfalls as part of an amphidromous life cycle, allowing them to re-penetrate adult upstream habitats after being swept out to the ocean upon hatching. The importance of climbing for juvenile stream gobies is well established, but adult fishes in upstream island habitats also face potential downstream displacement by catastrophic disturbances. Thus, retention of climbing ability could be advantageous for adult stream gobies. Climbing performance might be expected to decline among adults, however, due to the tendency for mass specific muscular power production to decrease with body size, and a lack of positively allometric growth among structures like the pelvic sucker that support body weight against gravity. To evaluate changes in waterfall climbing ability with body size in Hawaiian stream gobies, we compared climbing performance and kinematics between adults and juveniles from three species (Awaous guamensis, Sicyopterus stimpsoni, and Lentipes concolor). For species in which juveniles climbed using "powerbursts" of axial undulation, adult performance and kinematics showed marked changes: adult $A$. guamensis failed to climb, and adult $L$. concolor used multiple pectoral fin adductions to crutch up surfaces at slow speeds, rather than rapid powerbursts. Adult S. stimpsoni, like juveniles, still alternated attachment of oral and pelvic suckers to "inch" up surfaces and climbed at speeds comparable to those of juveniles. However, unlike juveniles, adult S. stimpsoni also add pectoral fin crutching to every climbing cycle. Thus, although powerburst species appear particularly susceptible to size-related declines in waterfall climbing performance, the addition of compensatory mechanisms prevents complete loss of this novel function in at least some species. 


\section{Introduction}

Many of the functional demands that animals face result from the physical forces placed on them by the external environment. As animals grow, these forces may change as a function of an animal's increase in size. To accommodate growth-related changes in external forces, animals might exhibit compensatory mechanisms such as allometric growth of support or propulsive structures (Carrier, 1983, 1996; Toro et al., 2003; Blob, 2006), or changes in behavior (Higham et al., 2005), that help to maintain functional performance at a comparable level throughout growth. Alternatively, without such mechanisms, the performance of some functions could decrease as juveniles mature into adults, even if those functions might continue to be advantageous among larger individuals (Maie, Schoenfuss \& Blob, in review).

The freshwater fauna of small volcanic islands are faced with particularly challenging environmental conditions. Streams on these islands are commonly subject to flash floods, high velocity flows, and waterfalls that obstruct access to upstream reaches (Fitzsimons \& Nishimoto, 1995). Although the physical forces exerted by these hazards can be quite rigorous for stream-dwelling animals, many species have evolved novel life history strategies and functional capacities that allow them to accommodate such demands. For example, in the Hawaiian Islands, the five native species of stream fishes (four gobies and one eleotrid: Fitzsimons, Nishimoto \& Yuen, 1993) hatch in freshwater but are swept by currents to the ocean, where they share an oceanic larval phase for several months before returning to freshwater habitats as juveniles (Ego, 
1956; Fitzsimons \& Nishimoto, 1995, 1996; Julius, Blob \& Schoenfuss, 2005). Two of these species (Eleotris sandwicensis and Stenogobius hawaiiensis) stay in lower stream reaches for the rest of their lives as they grow into adults. However, the three remaining species face further challenges because the adult stream habitats to which they return are in upstream reaches that are frequently obstructed by waterfalls ranging from hundreds to thousands of body lengths in height (Fitzsimons \& Nishimoto, 1995; Schoenfuss \& Blob, 2003). Juveniles of these species have been observed using two different mechanisms to climb these waterfalls (Nishimoto \& Kuamo'o, 1992;

Schoenfuss \& Blob 2003; Blob et al., 2006). Juveniles of Awaous guamensis and Lentipes concolor propel themselves against falling water by using rapid "powerbursts" of axial undulation initiated by pectoral fin adduction, which are then followed by periods of rest during which fish adhere to the substrate using a ventral sucking disc formed by fusion of the pelvic fins. In contrast, the third species, Sicyopterus stimpsoni, slowly inches up vertical surfaces by alternately attaching the pelvic disc and a second, oral disc to the substrate with little or no fin motion or axial undulation. The ability of juvenile gobies to scale waterfalls using these mechanisms allows the repopulation of upstream habitats by oceanic larvae even after catastrophic disturbances such as floods or hurricanes (Fitzsimons \& Nishimoto, 1995, 1996).

The importance of climbing to the juvenile life stages of $A$. guamensis, $L$. concolor, and S. stimpsoni has been well established by previous studies. However, adult fishes in upstream Hawaiian habitats face the same demanding environmental conditions as juveniles, such as rapid stream flows and displacement by catastrophic disturbances (Fitzsimons \& Nishimoto, 1995). As a result, the retention of climbing 
ability could be a considerable advantage to adult fishes. However, as body size increases among adult fishes, their ability to climb waterfalls might decline for several reasons. First, given the potential for mass specific power production to decrease with body size (Wilson, Franklin \& James, 2000; Irschick et al., 2003; Toro et al., 2003), sizerelated limits to power production might restrict the maximum body size at which "powerbursting" in particular is a viable style of climbing (Blob et al., 2006). This factor might limit the ability of $A$. guamensis and $L$. concolor to climb as adults, or force these species to adopt different climbing mechanics. Power demands might not substantially limit climbing by S. stimpsoni because of the slow cycle frequencies of inching and because this species keeps one sucker attached to the substrate throughout climbing bouts (Schoenfuss \& Blob, 2003). However, studies of ontogenetic scaling of body proportions in gobies (including S. stimpsoni) have shown that the area of the pelvic sucking disc grows isometrically with body length (i.e., scales $\propto \mathrm{BL}^{2}$ ) and, thus, does not keep pace with increases in the mass of the body $\left(\propto \mathrm{BL}^{3}\right)$ that it must keep attached to the substrate (Maie et al., in review). As a result, even inching climbers like $S$. stimpsoni might experience a decline in waterfall climbing performance as they grow larger in size.

In this study we test for size-related changes in climbing performance and mechanisms by evaluating the climbing of adult Hawaiian stream gobies (A. guamensis, L. concolor, and S. stimpsoni) and comparing their performance and kinematics to previous data (Schoenfuss \& Blob, 2003; Blob et al., 2006) from juveniles of the same species. Because of possible limits to muscular power production and isometric scaling of the adhesive sucker, we expect the climbing performance of adults to decrease 
relative to the performance of conspecific juveniles. We expect these changes to be especially dramatic for powerburst climbing species because the high frequencies of their locomotor movements (Schoenfuss \& Blob, 2003) are particularly disadvantageous for the high power production that would be required for climbing by larger fishes. Thus, species that use powerburst climbing as juveniles also might require major changes in locomotor behavior if they are to climb successfully as adults.

\section{Materials \& Methods}

During three field seasons between 2003-2005, adult individuals of the waterfall climbing species of Hawaiian stream gobies were collected with 'opae nets (fine mesh nets with a narrow opening at the top of a bowl shaped basket) from their native habitats above waterfalls in the mid-stream (A. guamensis and S. stimpsoni) or upstream (L. concolor) reaches of Hakalau Stream on the Island of Hawai'i. Within two hours of capture, animals were transferred in stream water to a research facility provided by the Hawai'i Department of Land and Natural Resources, Division of Aquatic Resources (DAR). Animals were separated by species into small groups of three to five individuals and then acclimated together for several hours at ambient stream temperatures $\left(19^{\circ} \mathrm{C}\right)$. Trials were conducted on individuals that overlapped in body size (Table 1).

Our experimental arena consisted of a climbing chute that extended up from a catch basin (adapted from Blob et al., 2006). The basin was $60 \mathrm{~cm}$ long $x 45 \mathrm{~cm}$ wide $x$ 
$15 \mathrm{~cm}$ deep, half filled with acclimated Hakalau stream water and contained a rock to provide cover for the fish. Climbing chutes were constructed from $1.5 \mathrm{~m}$ long sections of 4-inch diameter PVC pipe (cut in half longitudinally) and were extended from the basin at $57^{\circ}$ from horizontal. To generate flow over the climbing surface, a siphon was used to direct acclimated Hakalau stream water from a 20 I bucket down the chute at a flow rate of $200 \mathrm{ml} \mathrm{min}^{-1}$ (within the range of flow rates these fish encounter in nature: HLS, pers. obs.). We began each climbing trial by introducing groups of three to five fish (from a single species) into the catch basin with water flowing down the chute. If climbing did not commence within 20 min of the introduction of the fish, all animals were removed and a new group of fish was placed into the basin.

Climbing performance and kinematics were tested on chutes with fine-grained sand (grain size mean \pm S. D. $=392 \pm 99 \mu \mathrm{m}$; range $250-675 \mu \mathrm{m} ; \mathrm{n}=50$ ) attached to the pipe with spray glue. For several days prior to the climbing trials, stream water was run over these chutes to remove any chemical residue. A distance scale was marked on the cut surface of each PVC chute, out of sight of the climbing fish.

Two types of video records were collected from these trials. First, to measure climbing performance over a distance of several body lengths, a Sony DTV 1020 digital camcorder was used to film animals in dorsal view at a framing rate of $30 \mathrm{~Hz}$ as they climbed up the chute. The camera's field of view was adjusted to cover a $20 \mathrm{~cm}$ segment of pipe approximately $10 \mathrm{~cm}$ above the water level in the catch basin (water level in the catch basin varied slightly as water drained from the chute into the basin). Each animal was used in only a single trial and then returned to the stream. To follow Hawaiian tradition, we also returned the rock providing cover for the fish to the stream at 
the end of the filming sessions. Trials were only analyzed if video records indicated that the fish had climbed the entire $20 \mathrm{~cm}$ segment. Footage from mini DV tapes was transferred to an Apple Macintosh G4 computer using iMovie software. One of us (MB) tracked individual animals frame by frame in the videos. The beginning and end of each climbing bout was recorded, as were rest periods between sequential climbing bouts. In addition, instances of pectoral fin and tail use during climbing bouts were also recorded.

Second, to evaluate details of climbing kinematics for adult gobies, high-speed digital video recordings were collected for a subset of trials using either a Phantom V4.1 $(200 \mathrm{~Hz})$ or Redlake Motionscope $(250 \mathrm{~Hz})$ high-speed camera. Fish were filmed in dorsal view as they climbed up the chute (as in $30 \mathrm{~Hz}$ videos). High-speed video sequences of climbing were saved as .AVI files, and the positions of landmarks on the bodies of the fishes were digitized for each frame of analyzed climbing cycles using a modification of the public domain NIH Image program for Apple Macintosh, developed at the U.S. National Institutes of Health and available on the internet at http://rsb.info.nih.gov//nih-image/ (the modification, Quicklmage, was developed by J. Walker and is available at http://www.usm.maine.edu/ walker/software.html). For the inching climber S. stimpsoni, points at the base and tip of both pectoral fins were digitized along with four points on the head representing the maximal anterior, left, and right margins of the oral sucker, as well as the midpoint between the eyes. At least nine additional points along the midline body axis were also digitized, with the most posterior point representing the base of the caudal peduncle. For powerburst climbing species without an oral sucker, the same points were digitized except for those on head, for 
which the three sucker landmarks for S. stimpsoni were replaced with points at the anterior midline of the face and the left and right eyes.

Custom programs written in Matlab 5.0 (Mathworks, Inc.; Natick, MA, USA) were used to calculate kinematic variables from digitized coordinate data. For all trials, fin movements and the displacement of the front lip through the course of each cycle were evaluated. To quantify fin movements, the angle of each fin relative to the direction of travel (determined by the two midline head points) was calculated for each frame, allowing us to calculate a profile of fin movements throughout locomotor cycles and determine fin excursion angles. In addition, for S. stimpsoni, an index of the instantaneous area of the oral sucker also was calculated as:

$$
\text { mouth area }=(\pi / 4)\left(D_{L R}\right)\left(D_{A P}\right)
$$

where $D_{L R}$ is the instantaneous distance between the left and right edges of the mouth, and $D_{A P}$ is the instantaneous distance from the point between the eyes to the point marking the anterior edge of the mouth. This index simplifies the shape of the mouth and, therefore, does not measure the actual area of the oral disc; however, it allows us to evaluate changes in anteroposterior and lateral mouth dimensions that effectively track whether the oral disc is increasing or decreasing in area (Schoenfuss \& Blob, 2003). After evaluating these parameters, we used QuickSAND software (Walker, 1998; program available at http://www.usm.maine.edu/ walker/software.html) to fit a quintic spline to the kinematic calculations for each trial, smooth the data, and normalize 
all trials to the same duration in order to calculate mean kinematic profiles for each variable.

Statistical analyses were performed using GraphPad Prism version 4.0c for Macintosh (San Diego, California, USA) or Statview 5.0 for Macintosh (SAS Institute, Inc., Cary, NC, USA). Mean durations of single locomotor cycles were calculated from high-speed video trials, whereas mean durations of climbing and rest periods for entire bouts of climbing (over the $20 \mathrm{~cm}$ distance) were calculated from standard video trials. Net climbing speed (accounting for rest periods) was calculated by dividing the $20 \mathrm{~cm}$ distance climbed by the sum of the climbing and rest times. In addition, the percentage of time that each individual spent in motion (described as "duty factor" by Weinstein, 2001) was calculated as the time spent in motion divided by the sum of the motion and rest time periods. The significance of differences in kinematic and performance variables between species and between juveniles and adults of the same species were evaluated using non-parametric Mann-Whitney $U$ tests.

\section{Results}

\section{Climbing by Adult Gobies: Intraspecific Comparisons to Juveniles}

Awaous guamensis

In stark contrast to the behavior of powerbursting juveniles (Schoenfuss \& Blob, 2003;

Blob et al., 2006), none of 10 adult $A$. guamensis successfully climbed (or even 
attempted to climb) the experimental apparatus. Since adults of the other two focus species were able to climb (see following sections), and field and lab experience have not indicated adult $A$. guamensis to be especially skittish in their behavior (RWB, TM \& HLS, pers. obs.), the failure of $A$. guamensis to climb seems unlikely to be an artifact of the climbing apparatus itself or our experimental design. On the contrary, the lack of climbing by $A$. guamensis corresponds to observations from Kaua'i populations, in which streams devastated by Hurricaine Iniki showed delays of several months before the reappearance of reproductive adult $A$. guamensis (Fitzsimons \& Nishimoto, 1995). [HEIKO - see note in Discussion about checking accuracy of this statement]

Sicyopterus stimpsoni

Much like juvenile S. stimpsoni, adults use inching movements to climb waterfalls (Figs. 2a-d, 3a-e). As in juveniles, adult climbing cycles begin with a decrease in mouth area (Fig. 3b, d), reflecting detachment of the oral sucker from the substrate (Schoenfuss \& Blob, 2003). During this time there is little forward advancement of the body in adults until the minimum mouth area (i.e., sucker detachment) is achieved (Fig. 3c-d). However, unlike climbing by juveniles, in adult $S$. stimpsoni each climbing cycle is accompanied by moderate angular excursions of the pectoral fins (Figs 2a-d, 3e). From an initial position with the pectoral fin tips pointed posteriorly, by mid-cycle the fins abduct anteriorly to an angle nearly $40^{\circ}$ from a vector pointing posteriorly along the body midline (Table 1; Figs. 2a-c, 3e). This position is held through the middle third of the climbing cycle (Fig. 3e), during which time the body begins to advance (Fig. 3c). 
Thus, initial pectoral fin movements may put the fins into a position that helps to hold adult S. stimpsoni in place on the substrate, but initial forward movement of adults in this species appears to be achieved strictly through advancement of the head. Advancement of adults through the final third of the climbing cycle, however, is synchronous with adduction of the pectoral fins back to their initial position, suggesting that the pectoral fins might make contributions to climbing propulsion in adult $S$. stimpsoni that are not observed in juveniles. Some individuals made occasional moderate bending movements of the distal tail during some climbing cycles, but this behavior occurred irregularly. Because climbing proceeded for many cycles without these movements, they do not appear necessary for climbing to succeed.

With regard to climbing performance, adults show a small (0.016 s), statistically significant increase in climbing cycle duration compared to juveniles, but a much larger (and significant) decrease $(\sim 37 \%)$ in the duration of climbing bouts (i.e., sequences of consecutive climbing cycles: Table 1). In absolute terms, adult S. stimpsoni climbed the $20 \mathrm{~cm}$ distance significantly (>3 times) faster than juveniles; however, the adults evaluated were almost 2.5 times larger than juveniles, and a difference in climbing speed was no longer evident between juveniles and adults when their speeds were normalized by body length (Table 1). In fact, when climbing speed was calculated based only on the duration of time that fish were actually moving (i.e., speed during motion without consideration of time spent resting between bouts of consecutive climbing cycles), juveniles are slightly (but significantly) faster than adults (Table 1). Adults spent a greater portion of time than juveniles moving, rather than resting ( $67 \pm 16 \%$ versus $54 \pm 21 \%)$, but high variance in these measurements decreased our 
power to reject the null hypothesis of no difference between adults and juveniles in this parameter.

\section{Lentipes concolor}

L. concolor adults showed dramatic changes in climbing kinematics compared to juveniles, changes that are so substantial that it is inappropriate to describe adult $L$. concolor as "powerburst" climbers. First, in contrast to juveniles, in adult $L$. concolor rapid undulation of the body axis is absent during climbing (Fig. 2e-h). In addition, adult L. concolor use a sequence of pectoral fin abduction and adduction with every locomotor cycle, not just a single phase of fin adduction to initiate a climbing bout. Unlike juveniles, in which the pectoral fins are only adducted once to initiate a bout of climbing (Schoenfuss \& Blob, 2003), in adults a cycle of pectoral fin abduction and adduction accompanies every climbing cycle. Abduction begins early in the cycle, advancing to an average angle $107.1 \pm 29.2^{\circ}$ from a vector pointing posteriorly along the body midline, a value that does not differ significantly from that exhibited by powerburst climbing juveniles (Figs. 2f, 3g; Table 1). Pectoral fin adduction begins soon after the peak abduction angle is achieved (Fig. 3g) and is closely followed by upward advancement of the body at approximately $60 \%$ through the climbing cycle (Figs. $2 \mathrm{~g}-\mathrm{h}$, 3f). As in S. stimpsoni, some L. concolor made moderate bending movements of the distal tail in some climbing cycles, but this behavior was irregular and climbing frequently took place without any lateral tail movements.

Climbing performance of adult $L$. concolor also shows some substantial differences from that of juveniles. Although the duration of adult climbing cycles is 
significantly (over ten times) longer than that of juveniles, the duration of climbing bouts does not increase significantly among large individuals (Table 1). Moreover, the absolute climbing speed of adults (not normalized for body size) is also not significantly different from that of juveniles (Table 1). As a result, climbing speeds normalized for body size are more than eight times lower in adult $L$. concolor than in juveniles (Table 1). To achieve even these lower levels of performance, adults must spend a significantly greater portion of time moving, rather than resting $(37 \pm 19 \%)$, compared to juveniles (22 $\pm 11 \%$ : Table 1$)$.

\section{Interspecific Comparisons of Adult Climbing in Hawaiian Stream Gobies}

Although the two species of Hawaiian stream gobies that retain the ability to climb as adults (S. stimpsoni and L. concolor) used different styles of climbing as juveniles (inching versus powerbursts), as adults the kinematics and performance of these species become much more similar. Pectoral fin excursion angles differ significantly between adults of these species (with greater angles achieved by L. concolor: Table 1), but similarity is demonstrated between the species because, unlike juveniles, $S$. stimpsoni and L. concolor adults both incorporate pectoral fin abduction/adduction sequences with every locomotor cycle (although fin adduction in L. concolor is more closely synchronized with body advancement: Fig. 3). Both species also show very similar locomotor cycle durations as adults (Table 1). Although mean cycle durations are still statistically different between adults of these species, the difference between adult $S$. stimpsoni and $L$. concolor $(0.251 \mathrm{~s}$ versus $0.229 \mathrm{~s})$ is much less than that 
between juveniles of these species $(0.235 \mathrm{~s}$ versus $0.02 \mathrm{~s}$ : Table 1$)$. Climbing bout durations show a similar pattern, with mean values for adults still significantly different between the species, but converging much more closely ( $4.7 \mathrm{~s}$ versus $2.7 \mathrm{~s}$ for $S$. stimpsoni and L. concolor, respectively) than is typical in juveniles ( $7.6 \mathrm{~s}$ versus $2.0 \mathrm{~s}$ ). Convergence in locomotor performance between adult $S$. stimpsoni and $L$. concolor is also evident through comparisons of their climbing speed. Although juvenile L. concolor are dramatically faster climbers than juvenile S. stimpsoni (Schoenfuss \& Bllob, 2003; Blob et al., 2006), as adults the climbing performance of these species is much more similar (Table 1; Fig. 4a-b). Specifically, speeds of $L$. concolor have converged on those of S. stimpsoni: speeds of adult S. stimpsoni differ little from those of juveniles when normalized for body length, but speeds of adult $L$. concolor have decreased substantially from those of juveniles, so much so that adult $L$. concolor are significantly slower than adult S. stimpsoni (Table 1; Fig. 4b). One comparison that remains similar in adults to patterns observed in juveniles is that adult $S$. stimpsoni still spend a significantly longer portion of time in motion than adult $L$. concolor (Table 1; Fig. 4c). However, as noted previously, adults of both species show an increase in the portion of time spent moving over that observed in juveniles (Table 1).

\section{Discussion}

Body size has pervasive effects on animal function, many of which relate to changes in the forces that animals experience as they grow (McMahon, 1973; Schmidt-Nielsen, 
1984; LaBarbera, 1989; McHenry \& Lauder, 2005). Unless growing animals adopt mechanisms to accommodate these changing forces, the performance of a variety of functions might be impaired or precluded among larger individuals (Maie et al., in review). The three species of Hawaiian stream gobies capable of climbing waterfalls as juveniles show differing functional responses as they increase in size. In A. guamensis, the ability to climb waterfalls appears to have been lost among adult individuals. However, in the other two species of Hawaiian stream gobies, moderate to dramatic changes in locomotor kinematics appear to preserve at least some degree of climbing ability among adults, allowing continued opportunity for the use of this novel behavior to meet the functional requirements of a habitat with extreme physical demands.

\section{Ontogenetic Changes in Waterfall Climbing: Mechanisms for Accommodating Larger Body Size}

Two general mechanisms might enable animals to accommodate size-related increases in the locomotor forces that they experience (or must produce) as a result of growth: allometric increases in morphological features (e.g., fin length or breadth) or physiological parameters (e.g., muscle force generation); or, changes in locomotor behavior. Although morphological and physiological scaling have not been completely surveyed in climbing gobies, at least one morphological feature integral to climbing, the area of the pelvic sucker, fails to exhibit allometric growth that could help to accommodate the greater gravitational forces that must be resisted by larger individuals as they climb vertical surfaces (Maie et al., in review). This led us to predict that if adult 
gobies were able to climb successfully, they would be expected to show behavioral adjustments relative to juveniles that would facilitate the maintenance of climbing performance. Such adjustments appeared in both goby species (S. stimpsoni and $L$. concolor) that continued to climb as adults. In adults of both species, movements of the pectoral fins were added to every climbing cycle, contrasting with climbing patterns in juveniles in which the pectoral fins were used once (L. concolor) or not at all (S. stimpsoni) during climbing bouts. In S. stimpsoni pectoral fin movements are less extensive than in L. concolor and fin adduction is delayed until well after forward advancement has already commenced (Fig. 3c, e). Thus, extension of the fins may initially help stabilize the body of $S$. stimpsoni against the substrate during extension of the head, only aiding forward propulsion toward the end of each climbing cycle. In contrast, the broadly sweeping adductions of the pectoral fins in L. concolor are closely synchronized with upward advancement of the body, and appear to provide the primary upward thrust in this species in which axial motions are severely reduced compared to powerburst climbing juveniles.

Size-related changes in climbing performance and kinematics among the species that used powerburst climbing as juveniles were more drastic than those exhibited by the inching climber S. stimpsoni: one powerburst species (A. guamensis) did not climb as adults, and the other (L. concolor) shifted from using the body axis as a main propulsive structure to primary reliance on the pectoral fins. This divergence in climbing performance and mechanics between juveniles and adults suggests that powerbursts, as used by juveniles, may no longer be a viable climbing mechanism for larger individuals. A. guamensis and L. concolor do not appear incapable of performing the 
body movements associated with powerburst climbing as adults: the body axis movements seen among juvenile climbers (Schoenfuss \& Blob, 2003) can still be observed in swimming adults (RWB and HLS, pers. obs.), and the pectoral fin movements used by climbing adult $L$. concolor simply represent more frequent use of a behavior (performed over the same range of angles) exhibited by juveniles (Table 1). Instead, the use of powerburst climbing might be precluded because of its high demand for muscular power production (Blob et al., 2006). Ascension of vertical surfaces typically has high power requirements (Dial, 2003; Irschick et al., 2003), but muscles contracting at the high frequencies used during powerburst climbing tend to have reduced power producing capacities (Johnson et al., 1994; Rome et al., 1996; Rome, 1998). Because mass-specific power production also tends to decrease with body size (Wilson et al., 2000; Irschick et al., 2003; Toro et al., 2003), it might not be possible to climb using rapid movements at larger body sizes, leaving slower movements like pectoral fin crutching and the inching behavior of $S$. stimpsoni as the only viable mechanisms for adult gobies to use to scale waterfalls.

\section{Physiological Implications of the Climbing Performance of Adult Hawaiian Stream Gobies}

Like juveniles, both species that successfully climb waterfalls as adults still use intermittent bouts of locomotion during climbing. For other species moving over terrestrial substrates, the use of intermittent locomotion has the potential to significantly increase the distance that animals are able to travel before fatigue (Full \& Weinstein, 
1992; Weinstein \& Full 1992, 1998, 1999, 2000). This benefit results if pauses are of appropriate duration (absolute and relative to the time of motion) to allow the removal of fatigue-inducing products (such as inorganic phosphate) and the restoration of metabolic fuels (Weinstein \& Full, 2000; Allen \& Westerblad, 2001; Kramer \& McLoughlin, 2001). Intermittent bouts of inching by S. stimpsoni juveniles did not appear to meet these criteria (Blob et al., 2006), as their duration of activity ranged up to twice as long as their rest periods, a ratio that did not result in performance improvements in other studies (Weinstein \& Full, 1998, 1999). Adult S. stimpsoni did not differ significantly from juveniles in the ratio of time that they spent climbing versus resting (Table 1); thus, it appears that adults of this species are also unlikely to increase the distance that they travel before fatigue through the use of intermittent bouts of climbing. In contrast, juvenile powerburst climbers rest for time periods from three to five times longer than they spend moving (Blob et al., 2006). With the short durations of their periods of activity $(<2 \mathrm{~s})$, the distribution of motion and rest used by juvenile powerburst climbers is appropriate to increase their pre-fatigue travel distance (Weinstein \& Full, 1998, 1999) at the cold temperatures typical of their stream habitats (18-19 ${ }^{\circ} \mathrm{C}$ : Schoenfuss, Julius, \& Blob, 2004). Although adult L. concolor rested for a significantly shorter portion of their climbing trials than juvenile L. concolor, they still rested for over 1.7 times the duration of their activity periods (i.e., the ratio of motion to rest time was 0.59 ); in addition, adult locomotor bouts did not last significantly longer than those of juveniles (Table 1). This ratio of activity to rest periods is close to the ratio of 0.5 observed to increase distance capacity in species ranging from crabs to geckos (Weinstein \& Full, 1998, 1999). Thus, although adult L. concolor use climbing 
mechanisms substantially different from those of juveniles, they may still achieve some of the same performance benefits.

The slow speed of climbing by adult gobies may also help to prevent fatigue during this behavior. Climbing cycle frequencies for adult S. stimpsoni and L. concolor (calculated from climbing cycle durations listed in Table 1) average 4.0 and $4.4 \mathrm{~Hz}$, respectively, and climbing speeds for both species (considering periods of motion only) are less than 0.25 body lengths $\mathrm{s}^{-1}$ (Table 1 ). Motion at such low speeds and frequencies in fishes is typically powered by slow oxidative (red) muscle without accompanying activity in other fiber types (Jayne \& Lauder, 1993, 1994; Gillis, 1998; Altringham \& Ellerby, 1999). If adult gobies used only red muscle during climbing, their potential for fatigue could be reduced substantially because the activity of red muscle depends on aerobic metabolism that is well suited for endurance behaviors (Driedzic \& Hochachka, 1978; Sänger \& Stoiber, 2001). Extensive development of fast glycolytic (white) fiber would still be expected in adults of these species, however, as they would be of great importance for the swimming in rapid currents that likely constitutes the majority of locomotion in these animals.

\section{Ecological Implications of the Climbing Performance of Adult Hawaiian Stream Gobies}

The climbing performance exhibited by adult stream gobies can be related to several aspects of the ecology of these species. First, because A. guamensis juveniles have 
been shown to be the poorest climbers among juveniles of the three climbing stream goby species (Blob et al., 2006), it is not surprising that this species appears to have lost the ability to climb as adults that was retained by the other species we examined. Moreover, if climbing ability has been lost among larger A. guamensis, it would help to explain why this species showed the greatest delay in the upstream appearance of reproductive adults in streams on the island of Kaua'i that were devastated by Hurricaine Iniki in 1992, as repopulation may have been achieved solely by small individuals and juveniles migrating in from the ocean (Fitzsimons \& Nishimoto, 1995). [HEIKO - please check if you feel this statement in red is accurate - I only have the Env. Biol. Fishes paper to go on, not the one in the Devick volume].

One of the most striking features of the climbing behaviors exhibited by juvenile Hawaiian stream gobies is the diversity of climbing mechanisms and levels of performance that they employ. Not only do juveniles exhibit two dramatically different styles of climbing (inching versus powerbursts), but the performance exhibited by different species of powerburst climbers also differs dramatically. This diversity resembles the "many-to-one" mapping of morphology to function seen in studies of jaw function in labrid fishes (Alfaro, Bolnick \& Wainwright, 2005; Wainwright et al., 2005), and indicates that a wide range of performance capabilities can be maintained even under the strong selective pressures of extreme environmental conditions (Blob et al., 2006). However, among adult climbers this functional diversity appears to be diminished, suggesting a "fewer-to-one" mapping of performance to functional demand. [second half of previous sentence too over the top?] Although there are still statistically significant differences in the values of several performance variables between adult $S$. 
stimpsoni and L. concolor, the magnitude of those differences is considerably smaller between adults than it was between juveniles (Table 1). Moreover, adults of both species incorporate use of the same additional propulsive structure (adduction by the pectoral fins) beyond those seen in juveniles (Table 1). Thus, adult $S$. stimpsoni and $L$. concolor appear to have converged considerably in their strategies and capacity for climbing waterfalls. Although functional diversity might be maintained among juveniles of these species despite strong selective pressure for successful waterfall climbing, the additional pressures of increasing body size may finally limit the range of mechanics and performance that can be used to execute this novel behavior.

\section{Acknowledgements}

Funding for this study was provided by the Hawai'i Division of Aquatic Resources, Sport Fish Restoration Project (F-14-R-28) to HLS, MLJ, and RWB; the Clemson University Department of Biological Sciences, a Raney Award from the American Society of Ichthyologists and Herpetologists to TM, and Stearns Manufacturing Inc, St. Cloud, MN. We are grateful to Bob Nishimoto, Darrell Kuamo'o, Mike Fitzsimons, and Nora Espinoza for their suggestions and comments on this study, and to Christopher Mims for assistance with data analysis. We also thank Lance Nishiura, Troy Shimoda, Tim Shindo, and Bruce Kaya for access and logistical support at the DAR station in Hilo. 


\section{References}

Alfaro, M. E., Bolnick, D. I., \& Wainwright, P. C. (2005). Evolutionary consequences of many-to-one mapping of jaw morphology to mechanics in labrid fishes. Am. Nat. 165: E140-E154.

Allen, D. G., \& Westerblad, H. (2001). Role of phosphate and calcium stores in muscle fatigue. J. Physiol. 536: 657-665.

Altringham, J. D., \& Ellerby, D. J. (1999). Fish swimming: patterns in muscle function. J. Exp. Biol. 202: 3397-3403.

Blob, R. W. (2006). Scaling of the hindlimb skeleton in cynognathian cynodonts: implications for ontogeny and thermoregulation. In Amniote Paleobiology: Perspectives on the Evolution of Mammals, Birds, and Reptiles: 410-431. Carrano, M. T., Gaudin, T. J., Blob, R. W. \& Wible, J. R. (Ed.). Chicago: University of Chicago Press.

Blob, R. W., Rai, R., Julius, M. L., \& Schoenfuss, H. L. (2006). Functional diversity in extreme environments: effects of locomotor style and substrate texture on the waterfall climbing performance of Hawaiian gobiid fishes. J. Zool. (Lond.) 268:315324.

Carrier, D. R. (1983). Postnatal ontogeny of the musculo-skeletal system in the blacktailed jack rabbit (Lepus californicus). J. Zool. (Lond.) 201:27-55.

Carrier, D. R. (1996). Ontogenetic limits on locomotor performance. Physiol. Zool. 69:467-488. 
Dial, K. P. (2003). Wing -assisted incline running and the evolution of flight. Science 299: 402-404.

Driedzic, W. R. \& Hochachka, P. W, (1978). Metabolism in fish during exercise. In Fish physiology (Vol. VII): 503-543. Hoar, W. S. \& Randall, D. J. (Ed.). New York: Academic Press.

Ego, K. (1956). Life History of Fresh Water Gobies. Project No. 4-4-R. Fresh Water Game Fish Management Research. Honolulu, Territory of Hawai'i.

Fitzsimons, J. M., Nishimoto, R. T. \& Yuen, A. R. (1993). Courtship and territorial behavior in the native Hawaiian stream goby, Sicyopterus stimpsoni. Ichthyol. Explor. Freshwaters 4: 1-10.

Fitzsimons, J. M. \& Nishimoto, R. T. (1995). Use of fish behavior in assessing the effects of Hurricane Iniki on the Hawaiian island of Kaua'i. Environ. Biol. Fish. 43: $39-50$.

Fitzsimons, J. M. \& Nishimoto, R. T. (1996). Recovery of three Kaua'i streams from hurricane Iniki and implications for the restoration and regeneration of freshwater ecosystems in Hawai'i. In Will stream restoration benefit freshwater, estuarine, and marine fisheries?: 69-75. Devick, W. S. (Ed.). Honolulu.

Full, R. J. \& Weinstein, R. B. (1992). Integrating the physiology, mechanics, and behavior of rapid running ghost crabs: slow and steady doesn't always win the race. Am Zool. 32: 382-395.

Gillis, G. B. (1998). Neuromuscular control of anguilliform locomotion: patterns of red and white muscle activity during swimming in the American eel, Anguilla rostrata. J. Exp. Biol. 201: 3245-3256. 
Higham, T. E., Malas, B., Jayne, B. C., \& Lauder, G. V. (2005). Constraints on starting and stopping: behavior compensates for reduced pectoral fin area during breaking of the bluegill sunfish Lepomis macrochirus. J. Exp. Biol. 208: 4735-4746.

Irschick, D. J., Vanhooydonck, B., Herrel, A., \& Andronescu, A. (2003). Effects of loading and size on maximum power output and gait characteristics in geckos. J. Exp. Biol. 206: 3923-3934.

Jayne, B. C. \& Lauder, G. V. (1993). Red and white muscle activity and kinematics of the escape response of the bluegill sunfish during swimming. J. Comp. Physiol. A 173: 495-508.

Jayne, B. C. \& Lauder, G. V. (1994). How fish use slow and fast muscle fibers: implications for models of vertebrate muscle recruitment. J. Comp. Physiol. A 175: 123-131.

Johnson, T. J., Syme, D. A., Jayne, B. J., Lauder, G. V., \& Bennett, A. F. (1994). Modeling red muscle power output during steady and unsteady swimming in largemouth bass. Am. J. Physiol. 267: R481-R488.

Julius, M. L., Blob, R. W., \& Schoenfuss, H. L. 2005. The survival of Sicyopterus stimpsoni, an endemic amphidromous Hawaiian gobiid fish, relies on the hydrological cycles of streams: evidence from changes in algal composition of diet through growth stages of fish. Aquat. Ecol. 39:473-484.

Kramer, D. L., \& McLoughlin, R. L. (2001). The behavioral ecology of intermittent locomotion. Am Zool. 41: 137-153.

LaBarbera, M. (1989). Analyzing body size as a factor in ecology and evolution. Annu. Rev. Ecol. Syst. 20:97-117. 
Maie, T., Schoenfuss, H. L., \& Blob, R. W. (in review). Ontogenetic scaling of body proportions in waterfall-climbing gobiid fishes from Hawai'i and Dominica: implications for locomotor function.

McMahon, T. A. (1973). Size and shape in biology. Science 179:1201-1204.

McHenry, M. J., \& Lauder, G. V. (2005). Ontogeny of form and function: locomotor morphology and drag in zebrafish (Danio rerio). J. Morphol. 267:1099-1109.

Nishimoto, R. T., \& Kuamo'o, D. G. K. (1992). Waterfall climbing behavior in the postlarvae of native Hawaiian stream gobies. Technical paper, Division of Aquatic Resources, State of Hawai'i.

Rome, L. C. (1998). Some advances in integrative muscle physiology. Comp. Biochem. Physiol. B 120: 51-72.

Rome, L. C., Symes, D. A., Hollingsworth, S., Lindstedt, S. L., \& Baylor, S. M. (1996). The whistle and the rattle: the design of sound producing muscles. Proc. Nat. Acad. Sci. 93: 8095-8100.

Sänger, A. M. \& Stoiber, W. (2001). Muscle fiber diversity and plasticity. In Fish physiology (Vol. 18 ): 187-250. Johnston, I. A. (Ed.). San Diego: Academic Press. Schmidt-Nielsen, K. (1984). Scaling: Why is Animal Size so Important? Cambridge, Cambridge University Press.

Schoenfuss, H. L., \& Blob, R. W. (2003). Kinematics of waterfall climbing in Hawaiian freshwater fishes (Gobiidae): vertical propulsion at the aquatic-terrestrial interface. J. Zool. (Lond.) 261: 191-205. 
Schoenfuss, H. L., Julius, M. L., \& Blob, R. W. (2004). Colonization of a recent, volcanically formed freshwater habitat: an example of primary succession. Ichthyol. Explor. Freshwaters 15: 83-90.

Toro, E., Herrel, A., Vanhooydonck, B., \& Irschick, D. J. (2003). A biomechanical analysis of intra- and interspecific scaling of jumping and morphology in Caribbean Anolis lizards. J. Exp. Biol. 206: 2641-2652.

Wainwright, P. C., Alfaro, M. E., Bolnick, D. I., \& Hulsey, C. D. (2005). Many-to-one mapping of form to function: a general principle in organismal design? Int. Comp. Biol. 45: 256-262.

Walker, J. A. (1998). Estimating velocities and accelerations of animal locomotion: a simulation experiment comparing numerically different alogorithms. J. Exp. Biol. 201:981-995.

Weinstein, R. B. (2001). Terrestrial intermittent exercise: common issues for human athletics and comparative animal locomotion. Am Zool. 41: 219-228.

Weinstein, R. B. \& Full, R. J. (1992). Intermittent exercise alters endurance in an eightlegged ectotherm. Am J. Physiol. 262: R852-R859.

Weinstein, R. B. \& Full, R. J. (1998). Performance limits of low-temperature, continuous locomotion are exceeded when locomotion is intermittent in the ghost crab. Physiol. Zool. 71: 274-284.

Weinstein, R. B. \& Full, R. J. (1999). Intermittent locomotion increases endurance in a gecko. Physiol. Biochem. Zool. 72: 732-739. 
Weinstein, R. B. \& Full, R. J. (2000). Intermittent locomotor behaviour alters total work. In Biomechanics in animal behavior: 33-48. Domenici, P., \& Blake, R. W. (Eds.). Oxford: BIOS Scientific.

Wilson, R. S., Franklin, C. E., \& James, R. S. (2000). Allometric scaling relationships of jumping performance in the striped marsh frog, Limnodynastes peronii. J. Exp. Biol. 203: $1937-1946$. 


\section{FIGURE LEGENDS}

Figure 1 (a) Falls of Nanue Stream on the Hamakua Coast of the island of Hawai'i, a waterfall climbed by juveniles of all three species of climbing Hawaiian stream gobies: powerburst climbing Awaous guamensis and Lentipes concolor, and the inching climber Sicyopterus stimpsoni. (b) Photo of adult A. guamensis. (c) Photo of adult male $L$. concolor. (d) Photo of adult male S. stimpsoni.

Figure 2 Still images from high-speed video of adult Hawaiian stream gobies climbing up the chute of the artificial waterfall arena. (a-d) Sicyopterus stimpsoni. (e-h) Lentipes concolor. In each panel, left pectoral fin of the fish is outlined with a dashed line, and time (in milliseconds, ms) through a single climbing cycle for each species is indicated in the lower left corner of the panel.

Figure 3 Mean profiles of kinematic variables for Sicyopterus stimpsoni juveniles (a-b, $n$ = 26: data replotted for comparison with adults from Schoenfuss \& Blob, 2003), Sicyopterus stimpsoni adults (c-e, $n=23$ ), and Lentipes concolor adults (f-g, $n=32$ ). Plots for the same variable are organized in columns to facilitate comparison among these groups. Variables include cumulative displacement of the front lip since the start of the cycle, measured in body lengths $(a, c, f)$; instantaneous area of the mouth (i.e., oral sucker: b, d); and excursion angle of the pectoral fin (e, g). Each climbing cycle was normalized to the same duration and values of kinematic variables were interpolated for 25 equally spaced increments through the cycle using QuickSAND software (Walker, 1998). Plots for each variable illustrate means \pm 1 SE for each $4 \%$ 
increment of time through the cycle. Fin excursion angle was not plotted for juvenile $S$. stimpsonsi and mouth area was not plotted for adult $L$. concolor because these groups did not produce the movements represented by these variables. No plots are shown for adult Awaous guamensis because climbing was not elicited from adults of this species.

Figure 4. Box plots comparing (a) absolute climbing speed (in cm s-1), (b) relative climbing speed normalized for body length (in BL s-1), and (c) portion of time spent moving (\% time in motion) for adults of the Hawaiian stream gobies Sicyopterus stimpsoni $(n=25)$ and Lentipes concolor $(n=43)$. Speeds are calculated over the entire $20 \mathrm{~cm}$ climbing distance (see text) and account for periods of rest between bouts. For each plot, the box extends from $25^{\text {th }}$ to $75^{\text {th }}$ percentile, with a line indicating the median. Bars demarcate the range of values. ${ }^{* *}$ Significant difference at $P<0.001$ (Mann-Whitney U-test). 